\title{
A comparative study of magnetic resonance imaging and arthroscopy in internal derangement of knee
}

\author{
Vellanki Sarath $^{1, *}$, A. Srinivasa Rao ${ }^{2}$, K. Jyotsna Vibhari ${ }^{3}$ \\ ${ }^{1}$ Associate Professor, ${ }^{2}$ Professor and HOD, ${ }^{3}$ Post Graduate, Dept. of Orthodontics, Katuri Medical College \& Hospitals, \\ Chinakondrupadu, Guntur, Andhra Pradesh, India \\ * Corresponding Author: \\ Email: drsarathvellanki@ rediffmail.com
}

\begin{abstract}
The purpose of this study is to compare the findings of magnetic resonance imaging with arthroscopy in internal derangements of knee and to assess the sensitivity, specificity and accuracy of magnetic resonance imaging in comparison to arthroscopy.

Methods and Materials: Fifty six patients with history of suspected internal derangement of knee were evaluated prospectively with MRI and compared with arthroscopy during a one and half a year period from January 2016 to June 2017 at Katuri Medical College \& Hospitals, Chinakondrupadu, Guntur. 1.5 Tesla MRI machine using a closed extremity coil is used. Commonly used sequences in MRI of the knee include Turbo-spin echo (TSE), FFE (Gradient echo) and Short Tau Inversion Recovery (STIR) sequences in Axial, Sagittal and Coronal planes using a slice thickness of $3 \mathrm{~mm}$ with a $0.3 \mathrm{~mm}$ slice gap. Arthroscopy of the knee with standard anteromedial and anterolateral portals with the patient in supine position done in all the cases.

Observations: The diagnostic sensitivity, specificity and accuracy of MRI in detecting cruciate ligament and meniscal injuries as compared to arthroscopy is as follows: Anterior Cruciate Ligament (ACL): 97.29\%, 89.47\%, 94.64\% ; Posterior Cruciate Ligament (PCL): 100\%, 100\%, 100\%; Medial Meniscus (MM): 100\%, 93.33\%, 98.21\% and Lateral Meniscus (LM): 93.10 , 92.59, 92.85. Most common lesions found were ACL and Medial Meniscal tears (posterior horn of MM being the most common site).

Summary and Conclusion: MRI is a useful non-invasive modality having high sensitivity, specificity and accuracy in diagnosing cruciate ligament and meniscal injuries. MRI should be considered as the first line of investigation in all patients with suspected internal derangements of knee. MRI being easily available and non-invasive is useful as a pre-operative screening modality, thus improves the quality of diagnostic and therapeutic arthroscopies and further reduces the morbidity.

Arthroscopy is the gold standard in diagnosing cruciate ligament and meniscal injuries.
\end{abstract}

Keywords: Arthroscopy, MRI.

\section{Introduction}

The knee joint is one of the most vulnerable and frequently injured joints of the body. The injuries can be either acute or chronic and they constitute a major cause of pain and instability.

The various imaging modalities currently used to evaluate pathological conditions of the knee include conventional radiography, fluoroscopy, arthrography, sonography, computed tomography, nuclear medicine and magnetic resonance imaging.

The imaging of most pathological entities requires plain films. The use of fluoroscopy and sonography to guide interventional procedures and CT to evaluate complex fractures has become routine. The role of MRI in imaging of knee has steadily increased over the years and is often the main or only imaging tool for evaluation of suspected internal derangements of knee. ${ }^{1}$

The most significant advances in imaging of the knee has been made in the realm of magnetic resonance imaging, which has clearly emerged as a primary tool in evaluation and guiding the management of internal derangements of knee. With the development of newer sequences with improved SNR, higher resolution, shorter imaging times and improved accuracy, MRI has changed the traditional algorithm for workup of suspected internal derangements of knee.
Advantages of MRI over other imaging modalities include lack of ionizing radiation, excellent soft tissue contrast, multiplanar imaging capabilities, non-invasive and do not require manipulation of the knee as in Arthrography.

MRI Cartigram is showing promise in evaluation of cartilage lesions of the knee, which is now being increasingly done in many centres.

Arthroscopy is a minimally invasive surgical procedure in which an examination and sometimes treatment of damage of the interior of a joint is performed using an arthroscope, a type of endoscope that is inserted into the joint through a small incision. Arthroscopic procedures can be performed either to evaluate or to treat many orthopaedic conditions.

Knee arthroscopy has in many cases replaced the classic arthrotomy that was performed in the past. Today knee arthroscopy is commonly performed for treating meniscus injury, reconstruction of the anterior cruciate ligament and for cartilage microfracturing. Arthroscopy can also be performed just for diagnosing and checking of the knee; however, the latter use has been mainly replaced by magnetic resonance imaging.

During an average knee arthroscopy, a small fiberoptic camera (the arthroscope) is inserted into the joint through a small incision, about $4 \mathrm{~mm}$ (1/8 inch) 
long. A normal saline is used to visualize the joint parts More incisions might be performed in order to check other parts of the knee. Then other miniature instruments are used and the surgery is performed.

\section{Aims and Objectives}

1. To compare the findings of magnetic resonance imaging of Knee with arthroscopy in internal derangements of Knee.

2. To assess the sensitivity, specificity and accuracy of magnetic resonance imaging in comparison to arthroscopy.

\section{Materials and Methods}

Fifty six patients with history of suspected internal derangements of knee were evaluated prospectively with MRI and correlated with arthroscopy during a one and half a year period between January 2016 to June 2017 at Katuri Medical College \& Hospitals, Chinakondrupadu, Guntur. MR imaging was performed on a 1.5 Tesla (Philips Achieva) machine. Relevant clinical history and clinical findings were taken into consideration in performing MRI. In this study, arthroscopy was considered to be the gold standard and MRI finding were correlated.

Patient Positioning and Coil Selection: Patient is placed in supine position with the knee in a closely placed extremity coil. The patient's knee is placed in a relaxed position with slight external rotation $\left(15\right.$ to $\left.20^{0}\right)$ which facilitates the visualisation of ACL completely on sagittal images ${ }^{23}$. The knee is flexed slightly of about 5 to $10^{\circ}$ which increases the accuracy of assessing the patellofemoral compartment and patellar alignment. 57

Imaging Protocol and Pulse Sequences: Routinely used sequences in MR imaging of the knee include turbo-spin echo (TSE), FFE (Gradient echo) and Short Tau Inversion Recovery (STIR) sequences. The standard imaging planes used are Axial, Sagittal and Coronal views. Imaging protocols for MRI knee was done using a field of view (FOV) of $200 \times 200 \mathrm{~mm}, 256$ x 256 matrix and slice thickness of $3 \mathrm{~mm}$ with a 0.3 $\mathrm{mm}$ gap. An axial acquisition through the patellofemoral joint is used as an initial localiser for subsequent sagittal and coronal imaging planes.

Arthroscopy: Arthroscopy is a minimally invasive surgical procedure in which an examination and sometimes treatment of damage of the interior of a joint is performed using an arthroscope, a type of endoscope that is inserted into the joint through a small incision. Arthroscopy of knee can be done under spinal anaesthesia or general anaesthesia. Position of the patient is supine position. A tourniquet may be used around the thigh to help control bleeding during knee arthroscopy. Standard anteromedial and anterolateral portals of the knee are used. A narrow tube with a tiny camera on the end will be placed inside through one of the cuts. The camera is attached to a video monitor in the operating room. The surgeon looks at the monitor to see the inside of knee. Saline will be pumped into the knee to stretch the knee.

Arthroscopy was performed within a period of approximately one day to 20 days. Arthroscopy was performed by senior Orthopaedician. The MR images were reported by senior radiologists. In our study the orthopaedic surgeon performing the arthroscopy was aware of the MRI findings. Patients with grade 1 and grade 2 meniscal tears were excluded from the study as these lesions do not reach the articular surface and are not visualised during arthroscopy. The images were reviewed for the presence of ACL, PCL \&/or meniscal tears.

ACL and PCL tears were diagnosed based on the presence of any of the primary signs. Only grade 3 meniscal tears which extend to one of the articular surfaces were included in the study.

The sensitivity, specificity and accuracy of MRI was based on the findings of arthroscopy as arthroscopy was taken as the gold standard for the diagnosis of internal derangements of the knee.

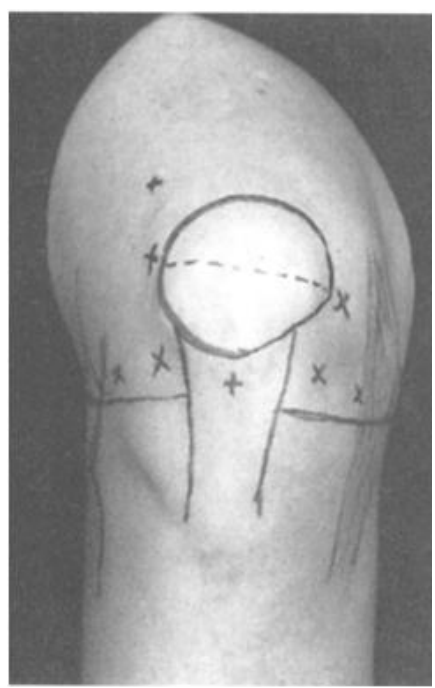

Fig. 1:

Anterior view of knee showing standard and optional portal sites and landmarks.

Diagnosis \& Modalities of Treatments: Internal derangement of knee injuries are easily diagnosed with careful history and physical examination of the knee. Patients present with history of twisting injury to knee in motion $\mathrm{C} / \mathrm{o}$ pain mild to moderate swelling locking/catching/click of the knee, inability to bend or straighten the knee, difficulty in squatting/climbing up stairs, limp, instability.
Evaluation of Meniscal injury by clinical test
1. Localised joint line tenderness
2. Mc Murray's test
3. Apley's test 
4. Squat test

5. Anterior and Posterior Drawer's test

6. Pivot shift test

7. Lachman's test

8. Varus /Valgus stress test

Investigation: Plane Radiography of the knee AP and lateral view were taken to rule out associated fracture, ligamentous avulsion, loose bodies, arthritic changes
Routine investigation to assess the fitness of the patient for procedure which are $\mathrm{Hb} \%$. TC, DC, ESR, BT/CT, RBS, Blood Urea, serum creatinine

Observations: A total of 56 patients in suspected internal derangements of knee were evaluated with MRI and subsequently by Arthroscopy. Out of 56 patients, 44 were males and 12 were females. Patients' age range from 14 to 65 years (mean of 35 yrs).

Fig. 2:
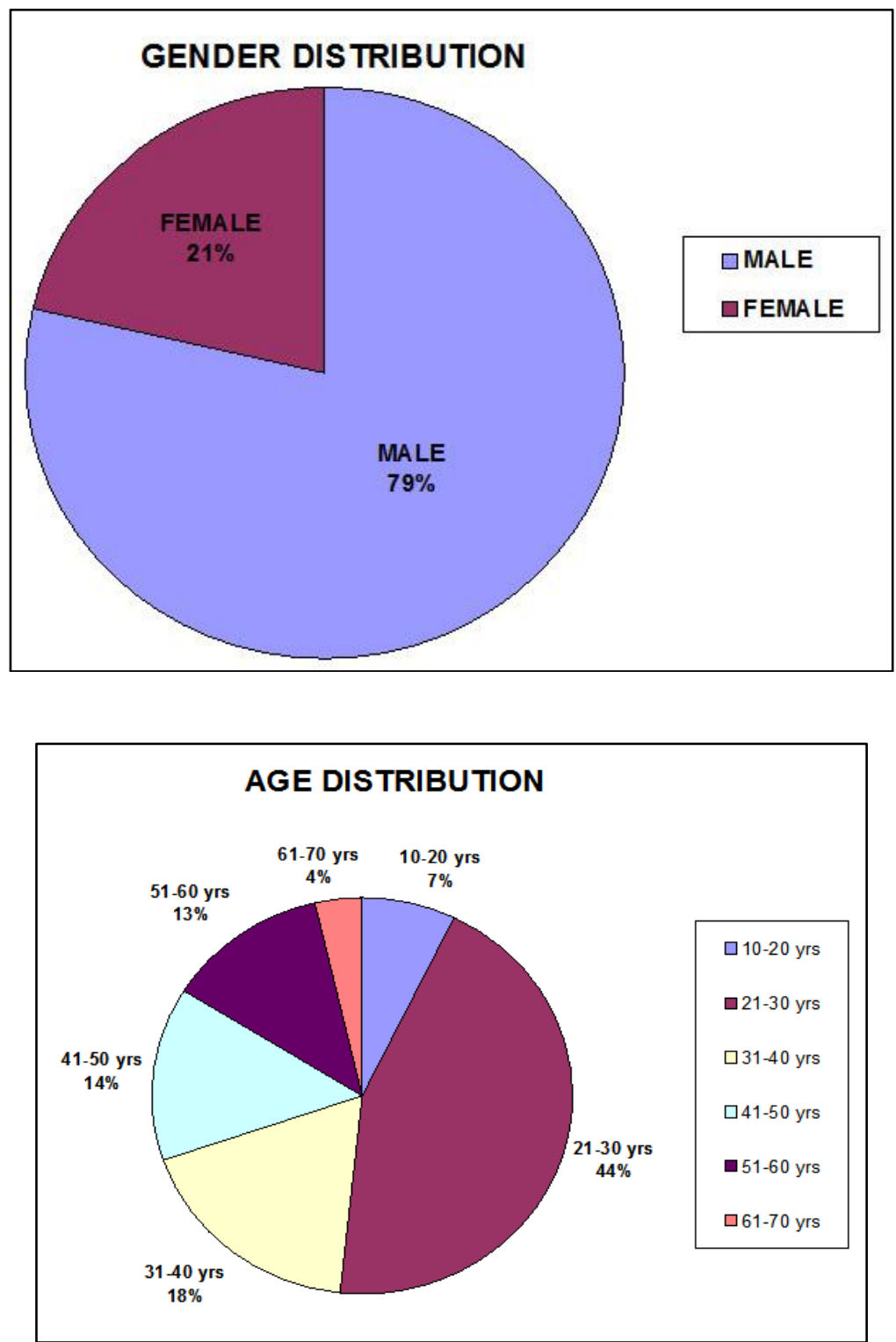

Fig. 3:

Table 1: Comparision

\begin{tabular}{|l|c|c|}
\hline & MRI & Arthros copy \\
\hline ACL & 38 & 37 \\
\hline PCL & 3 & 3 \\
\hline Medial meniscus & 42 & 41 \\
\hline Lateral meniscus & 29 & 29 \\
\hline
\end{tabular}




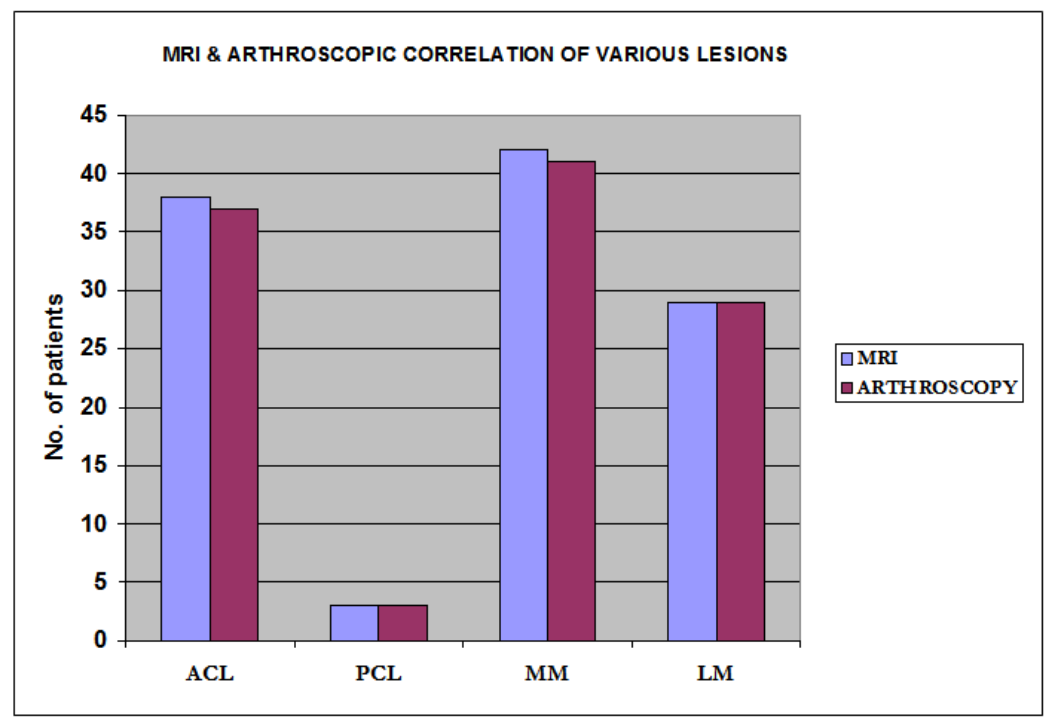

Fig. 4:

Cruciate Ligament Tears: Out of 56 patients, 38 cases showed ACL tears and 3 cases showed PCL tears. ACL tears were also associated with tears like meniscal tears and PCL tears. 28 out of 38 ACL tears showed associated meniscal tears. Buckling of PCL was seen in 7 cases of ACL tears. Isolated ACL tears were seen in 8 cases. Of the 3 cases of PCL tears, 2 cases were as sociated with ACL tears also.

MRI findings of ACL tears were correlated with arthroscopy. Sensitivity, specificity and accuracy of MRI in ACL tears were $97.29 \%, 89.47 \%$ and $94.64 \%$ respectively.

All the 3 patients who had PCL tears on MRI were reported to have PCL tears on arthroscopy. The diagnostic sensitivity, specificity and accuracy of MRI in diagnosing PCL tears are 100\% in this study.
Meniscal Tears: Out of 56 patients, 42 cases showed medial meniscal tears and 29 cases showed lateral meniscal tears. 27 cases of medial meniscal tears were associated with ACL tears and 18 cases of lateral meniscal tears were associated with ACL tears. Both meniscal tears were seen in 24 cases. 5 cases of bucket handle tears were seen in medial meniscus. Discoid meniscus with tear was seen in one patient, involving medial meniscus.

Out of 42 patients with medial meniscal tears, 3 cases showed tears in anterior horn, 7 cases showed tears in the body and 41 cases showed tears in the posterior horn.

Fig. 5:

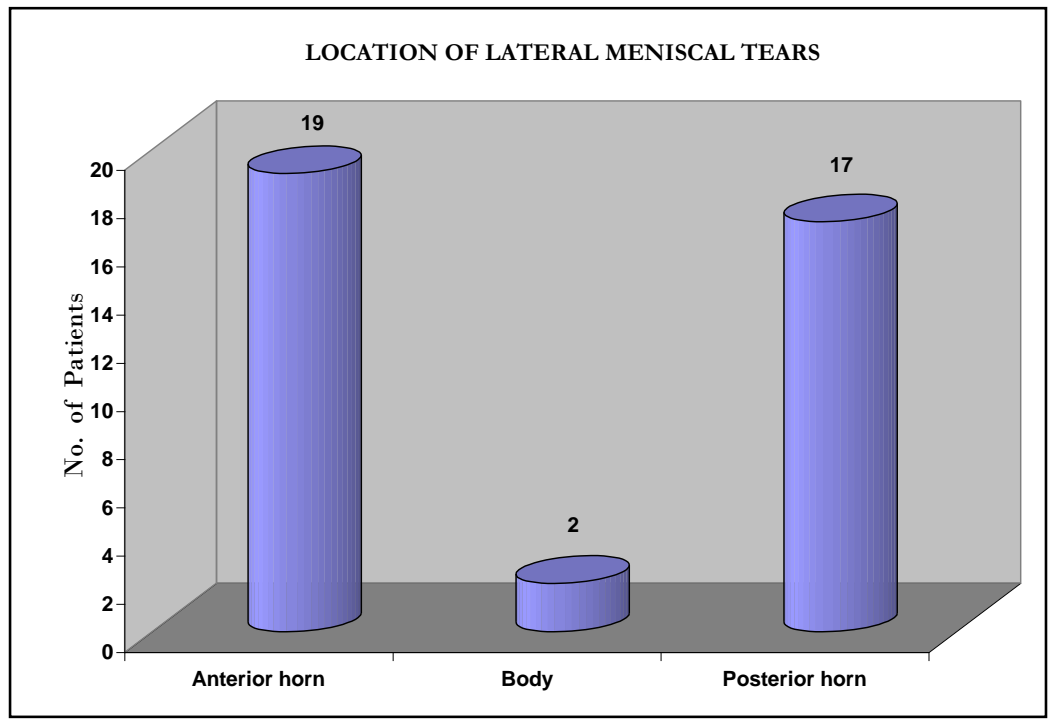


Out of 29 patients with lateral meniscal tears, anterior horn tears were seen in 19 cases, tears in the body were seen in 2 cases and posterior horn tears were seen in 17 cases.

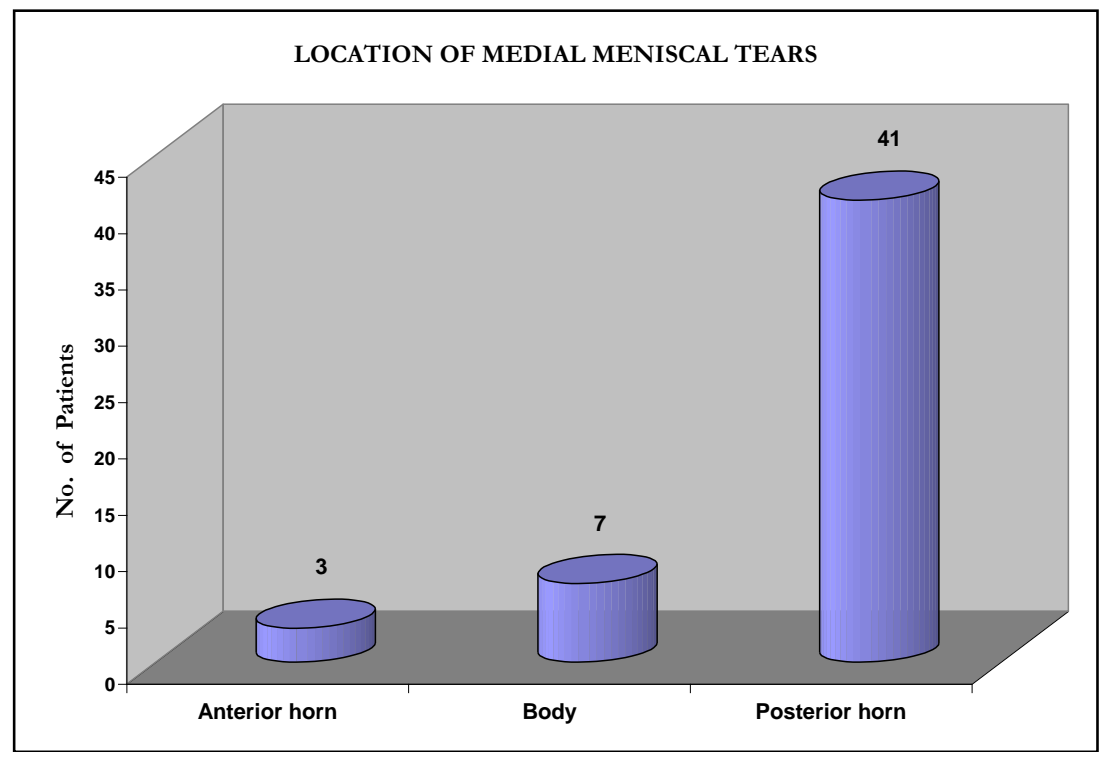

Fig. 6:

Table 2: Sensitivity, Specificity, Accuracy

\begin{tabular}{|l|c|c|c|c|}
\hline & ACL & PCL & Medial meniscus & Lateral Meniscus \\
\hline True positives & 36 & 3 & 41 & 27 \\
\hline False positives & 2 & 0 & 1 & 2 \\
\hline False negatives & 1 & 0 & 0 & 2 \\
\hline True negatives & 17 & 53 & 14 & 25 \\
\hline Sensitivity & 97.29 & 100 & 100 & 93.10 \\
\hline Specificity & 89.47 & 100 & 93.33 & 92.59 \\
\hline Positive predictive value & 94.73 & 100 & 97.61 & 93.10 \\
\hline Negative predictive value & 94.44 & 100 & 100 & 92.59 \\
\hline Accuracy & 94.64 & 100 & 98.21 & 92.85 \\
\hline
\end{tabular}

\section{Discussion}

Our study spanned over a $1 \frac{1}{2}$ year period from January 2016 to June 2017. Prospective evaluation of 56 patients with suspected internal derangements of knee with MRI and subsequently arthroscopy was done.

The cruciate ligaments and menisci were studied on both the modalities and comparisons were drawn.

Arthroscopy was considered as gold standard and the sensitivity, specificity and accuracy of MRI were calculated.

Of the 56 patients studied, there were $38 \mathrm{ACL}$ tears, 3 PCL tears, 42 medial meniscal tears and 29 lateral meniscal tears on MRI.

Cruciate Ligament Tears: The accuracy of MR imaging in assessing cruciate ligament tears has been reported to be high. MRI diagnosis of ACL tears was based on primary and secondary signs, as described earlier. Out of 56 patients, 38 ACL tears and 3 PCL tears were seen. Several studies including the study done by Carrino et $a l^{58}$ in 2002, reported that incidence of ACL tear is more common than PCL tear.
Out of 38 ACL tears on MRI, 2 cases were reported to be normal ACLs on arthroscopy (false positive). Rest of the 36 cases were confirmed on arthroscopy. One case which was reported to have an ACL tear on arthroscopy was reported as normal on MRI (false negative).

Two false positive cases of ACL tears were seen. One was because of intrasubstance hyperintensities, which was reported as normal on arthroscopy. The other case showed non-visualization of ACL, which may be contributed to ligament laxity.

One false negative case of ACL tear was identified, which probably is because of a partial tear. Studies by Yao et $a l^{59}$ and Umans et $a l^{60}$ showed that MR imaging has relatively low sensitivity but moderate to high specificity in diagnosing partial ACL tears.

In evaluating ACL tears, the sensitivity, specificity and accuracy in our study were $97.29 \%, 89.47 \%$ and $94.64 \%$ respectively. These results were comparable to the studies done by Fischer et $a l^{57}$ and Jackson et $a l^{31}$.

The role of MRI in diagnosing PCL tears is extremely accurate. In our study 3 PCL tears were seen, which were confirmed on arthroscopy. The sensitivity, 
specificity and accuracy of MRI in detecting PCL tears in this study was $100 \%$, which was comparable to the study done by Sonin et $a l^{37}$ where they have reported sensitivity, specificity and accuracy of 99 to $100 \%$.

Meniscal Tears: Role of MRI in assessing meniscal tears is extremely accurate. Patients with Grade III meniscal tears were only included in the study as Grade I and Grade II tears are not clearly visualized on arthroscopy. Out of 56 patients, 42 cases had Grade III medial meniscal tears and 29 cases had Grade III lateral meniscal tears. Both meniscal tears were seen in 24 cases.

Table 3: Diagnostic performance statistics for MRI of $\mathrm{ACL}^{23}$

\begin{tabular}{|l|c|c|c|c|}
\hline \multicolumn{1}{|c|}{ Reference } & No. of patients & Sensitivity & Specificity & Accuracy \\
\hline Mink et al & 242 & 92 & 95 & 95 \\
\hline Fischer et al & 997 & 93 & 93 & 93 \\
\hline Heron et al & 100 & 88 & 96 & 94 \\
\hline Kelly et al & 60 & 88 & 94 & 93 \\
\hline Jackson et al & 87 & 100 & 96 & 97 \\
\hline Lee et al & 41 & 94 & 100 & 98 \\
\hline Niitsu et al & 52 & 71 & 88 & 79 \\
\hline
\end{tabular}

Table 4: Diagnostic performance statistics for MRI of $\mathrm{PCL}^{23}$

\begin{tabular}{|l|c|c|c|c|}
\hline Reference & No. of patients & Sensitivity & Specificity & Accuracy \\
\hline Lee et al & 41 & 94 & 100 & 98 \\
\hline Niitsu et al & 52 & 100 & 96 & 96 \\
\hline Gross et al & 201 & 100 & 100 & 100 \\
\hline Fischer et al & 1014 & 80 & 99 & 99 \\
\hline
\end{tabular}

Table 5: Diagnostic performance statistics for MRI of medial meniscus ${ }^{23}$

\begin{tabular}{|l|c|c|c|c|}
\hline Reference & No. of patients & Sensitivity & Specificity & Accuracy \\
\hline Glashow et al & 50 & 77 & 71 & 74 \\
\hline Raunest et al & 50 & 94 & 37 & 72 \\
\hline Kelly et al & 60 & 97 & 77 & 88 \\
\hline Mandelabum & 80 & 96 & 82 & 90 \\
\hline Jackson et al & 87 & 98 & 89 & 94 \\
\hline Crues et al & 171 & 98 & 91 & 99 \\
\hline Spiers et al & 58 & 97 & 77 & 86 \\
\hline Quinn et al & 219 & 92 & 82 & 89 \\
\hline Fischer et al & 911 & 93 & 84 & 89 \\
\hline
\end{tabular}

Table 6: Diagnostic performance statistics for MRI of lateral meniscus ${ }^{23}$

\begin{tabular}{|l|c|c|c|c|}
\hline Reference & No. of patients & Sensitivity & Specificity & Accuracy \\
\hline Reicher et al & 43 & 75 & 84 & 81 \\
\hline Glashow et al & 50 & 93 & 94 & 94 \\
\hline Raunest et al & 50 & 78 & 69 & 72 \\
\hline Kelly et al & 60 & 90 & 87 & 88 \\
\hline Mandelabum & 80 & 75 & 95 & 91 \\
\hline Jacks on et al & 87 & 85 & 99 & 97 \\
\hline Crues et al & 171 & 96 & 98 & 98 \\
\hline Spiers et al & 58 & 100 & 97 & 97 \\
\hline Quinn et al & 219 & 70 & 95 & 87 \\
\hline Fischer et al & 911 & 68 & 94 & 88 \\
\hline
\end{tabular}

\section{Sum mary and Conclusions}

MRI is a useful non-invasive modality having high sensitivity, specificity and accuracy in diagnosing cruciate ligament and meniscal injuries.

Patients in the age group of 21-30 years accounted for maximum number of cases.
MRI is extremely useful in the evaluation of internal morphology and also the surface of the meniscus. MRI is more sensitive than arthroscopy in detecting intra substance tears and small peripheral meniscal tears. 
MRI should be considered as the first line of investigation in all patients with suspected internal derangements of knee. Arthroscopy should be reserved for selected cases where intervention is required and as a problem solving tool.

MRI being easily available and non-invasive is useful as a pre-operative screening modality, thus improves the quality of the arthroscopic evaluation and interventions and further reduces the morbidity.

\section{Financial Support and Sponsorship: Nil}

Conflicts of Interest: There are no conflicts of interest

\section{References}

1. Gray SD, Kaplan PA, Dussalt RG. Imaging of knee: current status. ONCA 1997;28(4):643-658.

2. Irizarry JM, Michael PR, MR Imaging of the knee ligaments and the postoperative knee, Radiologic clinics of North America 1997;35:45-76.

3. Rubin DA, George AP, Current concepts and controversies in Meniscal Imaging, 2000;8:243-270.

4. Kean DM, Worthington BS, Preston BJ, Nuclear MRI of knee: Examples of normal anat omy and pathology. $\mathrm{BrJ}$ Radiology 1983;56:355-361.

5. Moon KL, Genant HK, Helms CA, Chafetz NI, Crooks LE, Kaufman L: Musculoskeletal applications of nuclear MR Radiology 1983;147:161-171.

6. Li KC, Henkelman M, Poon PY, Robenstein J, MR Imaging of the knee $J$ Comput Assist Tomogra 1984;8:1147-1154.

7. Reicher MA, Rauschnig W, Gold RH, Basset LW, Lufkin RB, Glen W: High resolution MRI of the knee joint: Normal anatomy. AJR 1985;145;895-902.

8. Reicher MA, Basset LW, Gold RH: High resolution MRI of the knee joint: Pathological correlations. AJR 1985;145;903-909.

9. Hajek PC, Baker LL, Sartoris DJ, Neumann CH, Resnick D. Mr Arthrography: An anatomic - Pathologic investigation. Radiology 1987;163:141-147.

10. Kieser CW, Jackson RW (May 2001). "Severin Nordentoft: The first arthroscopist". Arthroscopy 17 (5):5325.doi:10.1053/jars.2001.24058. PMID 11337723.

11. CH Bennett \& C Chebli, 'Knee Arthroscopy'

12. Kieser CW, Jackson RW (2003). "Eugen Bircher (18821956) the first knee surgeon to use diagnostic arthroscopy". Arthroscopy 19 (7): $771-$ 6. doi:10.1016/S0749-8063(03)00693-5.PMID 12966386.

13. Böni T (1996). "[Knee problems from a medical history viewpoint]" (in German). Ther Umsch 53 (10): 716 23.PMID 8966679.

14. Watanabe M (1983). "History arthroscopic surgery". In Shahriaree H. O'Connor's Textbook of Arthroscopic surgery (1st ed.). Philadelphia: J.B. Lippincott.

15. Jackson RW (1987). "Memories of the early days of arthroscopy: 1965-1975. The formative years". Arthroscopy 3 (1): 1-3.doi:10.1016/S0749. 8063(87)80002-6. PMID 3551979.

16. Metcalf RW (1985). "A decade of arthroscopic surgery: AANA. Presidential address". Arthroscopy 1 (4):2215.doi:10.1016/S0749-8063(85)80087-6. PMID 3913437.

17. Allen FR, Shahriaree H (1982). "RichardL. O'Connor, M.D., 1933-1980" (PDF). J Bone Joint Surg Am 64 (2):315.
18. Spiers ASD, Meagher T, Ostlere SJ, Wilson DJ, Dodd CAF. Can MRI of the knee affect Arthroscopy practice? A prospective study of 58 patients. J Bone Joint Surg (Br) 1993;75(b):49-52.

19. Ruwe PA, Wright J, Randall RL, Lynch JK, Johl P, Mc Carthy. Can MR Imaging effectively replace diagnost ic Arthroscopy? Radiology 1992;183;335-339.

20. Noble J: Unnecessary Arthroscopy. Editorial J Bone Joint Surg (Br) 1992;74B:797-799.

21. Elvenes J, Jerome CP, Reikeras O, Johansen O. MRI as a screening procedure to avoid Arthroscopy for meniscal tears. Arch Orthop Trauma Surg 2000;120 (1-2):14-16.

22. Pappenport ED, Mehta S, Weislander SB, Lausten GS, Thomsen HS. MR Imaging before Arthroscopy in knee disorders? Acta Radiol 1996;37(5) 602-609.

23. Kaplan PA, Walker CW, Kilcoyne RF, Brown DE, Tusek D, Dussault RG. Occult fractures patterns of the knee associated with ACL tears. Assessment with MR Imaging. Radiology 1992;183:835-838.

24. Hollinshead WH. Anatomy for surgeons, vol 3, $3^{\text {rd }} \mathrm{Ed}$ New York: Harper and Row, 1982;563-583.

25. Remer EM, Fitzgerald SW, Friedman H, Rogers LF, Hendrix RW, Schafer MF. ACL injury: MR diagnosis and patterns of injury. Radiographics 1992;12:901-915.

26. Gentili A, seeger LL, Yao L, DoHM. ACL tear: Indirect sign at MRI: Radiology 1994;193:835-840.

27. Mink JH, Levy T, Crues JV. Tears of the ACL and menisci of the knee: MR evaluation. Radiology 1988;167:769-774.

28. Vahey TN, Broome DR, Keyes KJ, Shelbourne KD. Acute and Chronic tears of the ACL. Differential features of MR Imaging. Radiology 1991;181:251-253.

29. Tung GA, Davis LM, Wiggins ME, Fadale PD. Tears of the ACL: Primary and Secondary signs at MR Imaging. Radiology 1993;188:661-667.

30. Mc Cauley TR, Moses M, Kier R, Lynch JK, Barton JW Johl P. MR diagnosis of tears of ACL of the knee: importance of ancillary findings. AJR 1994;162:115-119.

31. Schweitzer ME, Cerville V, Kursunoglu Brahne S, Resnick D. The PCL line: an indirect sign of ACL injury. Radiology 1999;213:705-708.

32. Chan WP, Peterfy C, Fritz RC, Genant HK. MR diagnosis of complete tears of the ACL of the knee: Importance of anterior subluxation of tibia. AJR 1994;162:355-360

33. Vahey TN, Hunt JE, Shelbourne KD. Anterior translocation of the tibia. MR Imaging: A secondary sign of ACL tear. Radiology 1993; 187:817-819.

34. Murphy BJ, Smith RL, Uribe JW, Janecki CJ, Hetchman KS, Mangasarin RA. Bone signal abnormalities in posterolateral tibial and lateral femoral condyle in complete tears of ACL: a specific sign? Radiology 1992;182:221-224.

35. Kaplan PA, Gahl RH, Dussault RG, Anderson MW, Diduch DR. Bone contusions of the posterior lip of the medial tibial plateau (contrecoup injuries) \& associated internal derangements of the knee at MR Imaging. Radiology 1999;211(3);747-753.

36. Arndt WF, Traux AL, Barnett FM, Simmons GE, Brown DC. MR diagnosis of bone contusions of knee: comparision of coronal $\mathrm{T}_{2}$ weighted FSE with Fat Sat \& FSE STIR images with conventional STIR images. AJR 1996;166:119-124

37. Sonin AH, Fitzgerald SW, Friedman H, Hoff FL, Hendrix RW, Rogers LF. PCL injury: MR Imaging diagnosis and pattern of injury. Radiology 1994;190:455-458. 
38. Geissler WB, Whipple TL. Intraarticular abnormalities in associated PCL injuries. Am J Sports Med. 1993;21:846854.

39. Cherney S. The Knee. Principles of Orthopaedic practice, vol.2. $2^{\text {nd }}$ edition, New York: McGraw Hill, 1989;12831380 .

40. Schweitzer ME, Tran D, Deely DM, Hume EL. Medial collateral ligament injuries: evaluation of multiple signs, prevalence and location of associated bone bruises and assessment with MR Imaging. Radiology 1995;194:825829.

41. Yao L, Dungan D, Seeger LL. MR Imaging of Tibial collateral ligament injury: Comparision with clinical examination. Skeletal Radiology 1994;23:521-524.

42. Rubin DA, Kneeland JB, Listerud J, Underberg E, Davis SJ. MR diagnosis of meniscal tears if the knee: Value of FSE vs conv SE Pulse sequences. AJR 1994;162:11311138.

43. Stoller DW, Martin C, Crues JV, Kaplan L, Mink JH. Meniscal tears: Pathologic correlation with MR Imaging. Radiology 1987;163:731-735.

44. Crues JV, Mink JH, Levy T, Lotysch M Stoller DW, Meniscal tears of the knee. Accuracy of MI Imaging. Radiology 1998;164:445-448.

45. Lotysch M, Mink JH, Schwartz SA. Magnetic resonance imaging in the detection of meniscal injuries. Magnetic resonance imaging 1986;4:94.

46. Levinson ME, Baker BE. Prearthrotomy diagnostic evaluation of the knee: Review of 100 cases, diagnosed by Arthrography and arthroscopy. AJR 1980;134:107114.

47. Raunest J, Hotzinger H, Burrig KF. MRI and Arthroscopy in detection of meniscal derangements. Arthroscopy 1994;10:624-630.

48. Weiss KL, Morehouse HT, Levy IM. Sagittal MR images of the knee: A low signal band parallel to the PCL caused by a displaced bucket handle tear. AJR 1991;156:117119.

49. Singson RD, Feldman F, Staron R, Kieman H. MR Imaging of the displaced bucket handle tear of the medial meniscus. AJR 1991;156:117-119.

50. Wright DH, Desmet AA, Norres M. Bucket handle tears of the medial and lateral menisci of the knee: Value of MR Imaging in detecting displaced fragments. AJR 1995;165:621-625.

51. Helms CA Laorr A, Cannon WD. The absent bow-tie sign in bucket handle tears of the menisci in the knee. AJR 1998;170(1):57-61.

52. Watt $\mathrm{S}$, Tonya H, Nigel R. The value of the absent bowtie sign in MRI of bucket handle tears. Clinical Radiology 200;55:622-626.

53. Weiner B, Rosenberg N. Discoid medial meniscus associations with bone changes in the tibia. J Bone Joint Surg (AM) 1974;56: 171-176.

54. Mink JH, Levy T, Crues JV. Tears of the anterior cruciate ligaments and menisci of the knee. MR Imaging evaluation. Radiology 1998;167:769-774.

55. Arthur DeSmet, Norris MA, Yandow DR, Quintana FA, Graf BK, Keene JS. AJR 1993;161:101-107.

56. Araki Y, Ootoni F, T sukaguchi I. MR diagnosis of meniscal tears of the knee: Value of axial three dimensional fourier transformation GRASS images. AJR 1992;158:587-590.

57. Fischer SP, Fox JM, Del Pizzo W et al. Accuracy of diagnosis from magnetic resonance imaging of the knee: A multi-centre analysis of one thousand and fourteen patients. J Bone Joint Surg (Am) 1991;73 A:2-10.
58. Carrino JA, Schweitzer ME. Imaging of sports-related knee injuries. Radiology clinics of North America 2002;40:181-202.

59. Yao L, Gentili A, Lee K. Partial ACL rupture: An MR diagnosis? Skeletal Radiology 1995;24:247-251.

60. Umans H, Wimphfeimer O, Haramati $\mathrm{N}$ et al. Diagnosis of partial tear of the anterior cruciate ligament of the knee. Value of MR Imaging. AJR 1995;165:893-897.

61. La Prade RF, Burnett QM, Veenstra MA, Hodgman CG. The prevalence of abnormal MR findings in asymptomatic knees. Am J Sp Med 1994;171:761-766.

62. Mansfield GT, Youngberg RA, Warme W, Pitcher JD, Nguyen PL. Potential cost savings of MR Imaging obtained before arthroscopy of the knee: Evaluation of 50 consecutive patients. AJR 1997;168:913-918.

63. Bonamo JJ, Saperstein A. Contemporary magnetic resonance imaging of the knee: the orthopaedic surgeon's perspective. Mag Res imaging clinics Of North America 1994;2:481-495.

64. Quinn SF, Brown TF. Meniscal tears diagnosed with MR Imaging versus Arthroscopy: How reliable a standard is Arthroscopy? Radiology 1991;183:843-847.

65. Santosh Kumar, Arun Bansal: A Comparative Study of Accuracy of Clinical Examination, MRI \& Arthroscopy Findings in Cruciate Ligament and Meniscal Injuries of the Knee; Indian Journal of Basic \& Applied Medical Research; December 2011:Issue-1, Vol.-1, P. 106-113.

66. Abhi A.Mane, P.G. Kulkarni: To study and evaluate the MRI and arthroscopic findings in knee problems with special attention towards false positive $\&$ false negative reports; The Journal of Maharashtra Orthopaedic Association 2013;8(4):17-21.

67. Saurav Singla, Nitin Kansal: Senstivity and specificity of MRI versus arthroscopy in internal derangement of knee; International Journal of Scientific and Research Publications, Volume 3, Issue 4, April 20131 ISSN 2250-3153.

68. Nilton Orlando Júnior, Marcos George de Souza Leão and Nelson Henrique Carvalho de Oliveira: Diagnosis of knee injuries: comparison of the physical examination and magnetic resonance imaging with the findings from arthroscopy; 10.1016/j.rboe.2015.10.007. 